EGU2020-5873, updated on 29 May 2020

https://doi.org/10.5194/egusphere-egu2020-5873

EGU General Assembly 2020

(c) Author(s) 2020. This work is distributed under

the Creative Commons Attribution 4.0 License.

\title{
Variation of the tectono-magmatic activity along the Reykjanes Ridge: Influence of the Iceland hotspot on the accretionary processes
}

Morgane Le Saout ${ }^{1}$, Colin Devey ${ }^{1}$, Dominik Palgan ${ }^{2}$, Thorsten Lux ${ }^{1}$, Sven Petersen ${ }^{1}$, Daníel Pórhallsson ${ }^{3}$, Adrianna Tomkowicz ${ }^{2}$, and Saskia Brix ${ }^{4}$

${ }^{1}$ GEOMAR, Helmholtz Centre for Ocean Research Kiel, Germany

${ }^{2}$ Institute of Oceanography, University of Gdańsk, Poland

${ }^{3}$ Institute of Biology, University of Iceland, Reykjavík, Iceland

${ }^{4}$ Senckenberg am Meer, German Centre for Marine Biodiversity Research (DZMB), Hamburg, Germany

The Reykjanes Ridge is a $900 \mathrm{~km}$ long oblique slow-spreading ridge, formed by individual "en echelon" axial volcanic ridges (AVR), directly under the influence of the Iceland hotspot. From the Reykjanes Peninsula to the Bight fracture zone, the Reykjanes Ridge shows variations in lava chemistry, crustal thickness, thermal structure and ridge morphology, which has been attributed to this influence. Our study focuses on four areas of the ridge mapped and sampled during the cruise MSM75 in 2018. The northern area is characterized by the only known hydrothermal field discovered along the Reykjanes Ridge. The two central areas are located in a region of increasing magma supply. Finally, the southernmost area is underlined by the only magma body ever detected seismically below the Reykjanes Ridge. The analysis combines $15 \mathrm{~m}$ resolution shipbased bathymetry, ground-truthing from ROV dives and geochemical analysis of glass samples to look at variations of magma composition, fault density, seamount density and morphology along the ridge axis. Two major parameters influence the distribution and geometry of faults and seamounts: the distance from the hotspot and the accretion state of individual AVR (i.e., magmatic extension vs. tectonic extension). Fracture geometry is highly influenced by the depth of the brittleductile boundary that deepens with distance from the plume center, while fault density at the axis reflects different development stages of individual AVR. Seamount morphologies may also reflect individual AVR development, but we also show morphological variation with distance from the hotspot, correlated with the average variation in lava composition and mantle temperature. 